\title{
Treatment of glioblastoma multiforme cells with temozolomide-BioShuttle ligated by the inverse Diels-Alder ligation chemistry
}

\author{
Klaus Braun' \\ Manfred Wiessler' \\ Volker Ehemann ${ }^{2}$ \\ Ruediger Pipkorn ${ }^{3}$ \\ Herbert Spring ${ }^{4}$ \\ Juergen Debus ${ }^{5}$ \\ Bernd Didinger ${ }^{5}$ \\ Mario Koch ${ }^{3}$ \\ Gabriele Muller ${ }^{6}$ \\ Waldemar Waldeck ${ }^{6}$ \\ 'German Cancer Research Center, \\ Dept of Imaging and Radiooncology, \\ Heidelberg, Germany; ${ }^{2}$ University \\ of Heidelberg, Institute of Pathology, \\ Heidelberg, Germany; ${ }^{3}$ German \\ Cancer Research Center, Central \\ Peptide Synthesis Unit, Heidelberg, \\ Germany; ${ }^{4}$ German Cancer Research \\ Center, Dept of Structural Analysis \\ of Gene Structure and Function, \\ Heidelberg, Germany; ${ }^{5}$ University \\ of Heidelberg, Dept of Radiation \\ Oncology, Heidelberg, Germany; \\ ${ }^{6}$ German Cancer Research \\ Center,Division of Biophysics \\ of Macromolecules, Heidelberg, \\ Germany
}

\begin{abstract}
Recurrent glioblastoma multiforme (GBM), insensitive against most therapeutic interventions, has low response and survival rates. Temozolomide (TMZ) was approved for second-line therapy of recurrent anaplastic astrocytoma. However, TMZ therapy in GBM patients reveals properties such as reduced tolerability and inauspicious hemogram. The solution addressed here concerning GBM therapy consolidates and uses the potential of organic and peptide chemistry with molecular medicine. We enhanced the pharmacologic potency with simultaneous reduction of unwanted adverse reactions of the highly efficient chemotherapeutic TMZ. The TMZ connection to transporter molecules (TMZ-BioShuttle) was investigated, resulting in a much higher pharmacological effect in glioma cell lines and also with reduced dose rate. From this result we can conclude that a suitable chemistry could realize the ligation of pharmacologically active, but sensitive and highly unstable pharmaceutical ingredients without functional deprivation. The TMZ-BioShuttle dramatically enhanced the potential of TMZ for the treatment of brain tumors and is an attractive drug for combination chemotherapy.
\end{abstract}

Keywords: drug delivery, carrier molecules, facilitated transport, glioblastoma multiforme, temozolomide

\section{Introduction}

The Grade IV classification of glioblastoma multiforme (GBM) means that these tumors grow aggressively and rapidly. The tumor entity GBM is considered one of the most aggressive and intractable cancers. Despite all treatments including neurosurgical resection followed by postoperative radiotherapy, the overall survival times of patients are unsatisfactory (Walker et al 1978). Therefore our aim is to use the potential for temozolomide (TMZ) to treat GBM by improving drug's potency. The combination of the oral administration of TMZ with radiotherapy led to longer survival times (Combs et al 2005) by delaying tumor progression. Including simple oral application increased the interest in using TMZ to treat GBM (Osoba et al 2000). The action of TMZ (8-carbamoyl-3-methylimidazo [5,1-d]-1,2,3,5-tetrazin-4(3H)one) has been extensively studied, primarily in leukemia and lymphoma cells. TMZ is rapidly resorbed after oral application and spontaneously decomposes in aqueous solution at physiological $\mathrm{pH}$ to the cytotoxic methylating agent 5-(3-methyltriazen1-y1)imidazole-4-carboxamide (MTIC) (Tsang et al 1990). The cytotoxicity of TMZ appears to be mediated mainly through adduction of methyl groups to $\mathrm{O}^{6}$ positions of guanine $\left(\mathrm{O}^{6} \mathrm{mG}\right)$ in genomic DNA (Denny et al 1994) followed by recognition of this adduct by the mismatch repair system (MMR), which mispairs with thymine during the next cycle of DNA replication.

The half-life of TMZ (Riccardi et al 2003) in plasma and non-target-gene-specific alkylating mode of action can result in undesired adverse reactions which then hamper 
the therapeutic outcome efficiency. For this reason new TMZ-derivatives were designed. The use of the peptidebased nuclear localization sequence (NLS) (Braun et al 2002; Heckl et al 2002), which leads to an active nuclear targeting, could minimize existing handicaps. Because of their higher molecular mass and their physico-chemical characteristics the transport across the cellular membrane of TMZ-NLS peptide conjugates is still poor. Therefore a carrier molecule is needed, which can - after the transmembrane passage into the cytoplasm - discharge its TMZ-NLS-Cys cargo so that a sufficient concentration of pharmacologically active molecules can reach their target site in the nucleus.

In this context numerous viral (Tabin et al 1982; Seymour 1992; Advani et al 2002; Conlon and Flotte 2004; Palmer and Ng 2005) and non-viral (Bangham and Papahadjopoulos 1966; Derossi et al 1996; Storm and Crommelin 1997; Vives et al 1997; Bourne et al 2000; Merdan et al 2002) welldocumented transport vehicles were designed by different laboratories. They are able to facilitate the cellular transport of molecules with inappropriate physico-chemical properties for the transmembrane passage.

Our considerations for improving the transport of TMZ into the cell nucleus led to a search for suitable ligation modes of TMZ with a nuclear address peptide (a) which in turn is connected to carrier molecules (b) (Table 1).

A brief comment is required here for a better understanding of the following paragraphs. In chemistry the meaning of "ligation reaction" is the basis of Diels-Alder chemistry, on which we focus here, in contrast that in molecular biology, in which it means the ligase-catalized connection of nucleic acids at the 3'-hydoxy group and the 5'-phosphate terminus.

This first ligation (a) should permit a multi-modular connection of functional peptides and formation of higher peptide chain lengths compared to the different manufacturing techniques. It should also achieve a higher functional variability regarding the coupled peptides or substances in relation to mono-modular peptides generated by simple solid phase peptide synthesis or by recombinant chemistry. However the fast and selective covalent linkage of biologically active molecules under physiological conditions still represents a great challenge in the chemical praxis.

For this reason, such a ligation reaction should meet the following criteria:

(1) rapid course of the reaction, (2) independent of solvent properties, (3) no side reaction with other functional groups present in the molecule, (4) no special coupling-reagents, (5) an economical procedure, and (6) irreversible chemical reaction characteristics. The following ligation methods are favorable:

\section{Enzymatic methods}

The enzyme-mediated peptide ligation method is favorable to preserve native active structures of proteins and peptides (Anthony-Cahill and Magliery 2002). In this context the bacterial enzyme sortase (Mazmanian et al 1999) demonstrates an interesting approach: a transpeptidase that catalyzes a sequence-specific ligation of functional peptides harboring the ligand motif Gly-Gly-Gly to the amino terminus of the target molecule or peptide (Parthasarathy et al 2007).

\section{Chemical methods}

The 'Staudinger ligation', which is based on the reaction of phosphines with azides under nitrogen elimination, is proposed as a further convenient candidate for ligation reactions (Kohn and Breinbauer 2004; Chandra et al 2006). The second chemical reaction useful for ligation is the thioester-method, which has been described by different groups (Camarero et al 2004; Yeo et al 2004). A method recently described demonstrates a ligation of $\alpha$-ketoacids and $\mathrm{N}$-alkylhydroxylamines under production of $\mathrm{CO}_{2}$ and water as by-products (Bode et al 2006). A further concept, the modular 'click chemistry', uses the most practical and reliable chemical transformations and could be considered a promising platform. Its applications are increasingly found in all aspects of drug discovery, ranging from offering valuable clues in combinatorial chemistry and target-templated in situ chemistry, to proteomics and DNA research, using bioconjugation reactions (Kolb et al 2001; Kolb and Sharpless 2003). In this concept the 1,3-dipolar cycloaddition, considered as 'cream of the crop' (Rostovtsev et al 2002), represents a prime example of the electrocyclic reactions developed by Huisgen (Huisgen 1984).

\section{Method used in our experiments}

Our ligation approach is based on cycloaddition reactions via the pericyclic Diels-Alder reaction (DAR) with 'inverseelectron-demand', which is a modification of $\pi$-electrondeficient N-heteroaromatics with electron-rich dienophiles (Bachmann and Deno 1949). The main open question was how to circumvent the reversibility of conventional DAR. Here we used tetrazine-structures harboring electron-pure dienes permitting an irreversible reaction by formation of molecular nitrogen (Kim et al 2005).

We reveal how proper chemistry contributes to optimization of pharmacological properties of an already efficient drug such as TMZ, thereby possibly extending the spectrum of tumor entity treatments. 
Table I Schematic pattern of the TMZ-NLS and transport-peptides modules (modular schemata of the TMZ-BioShuttle)

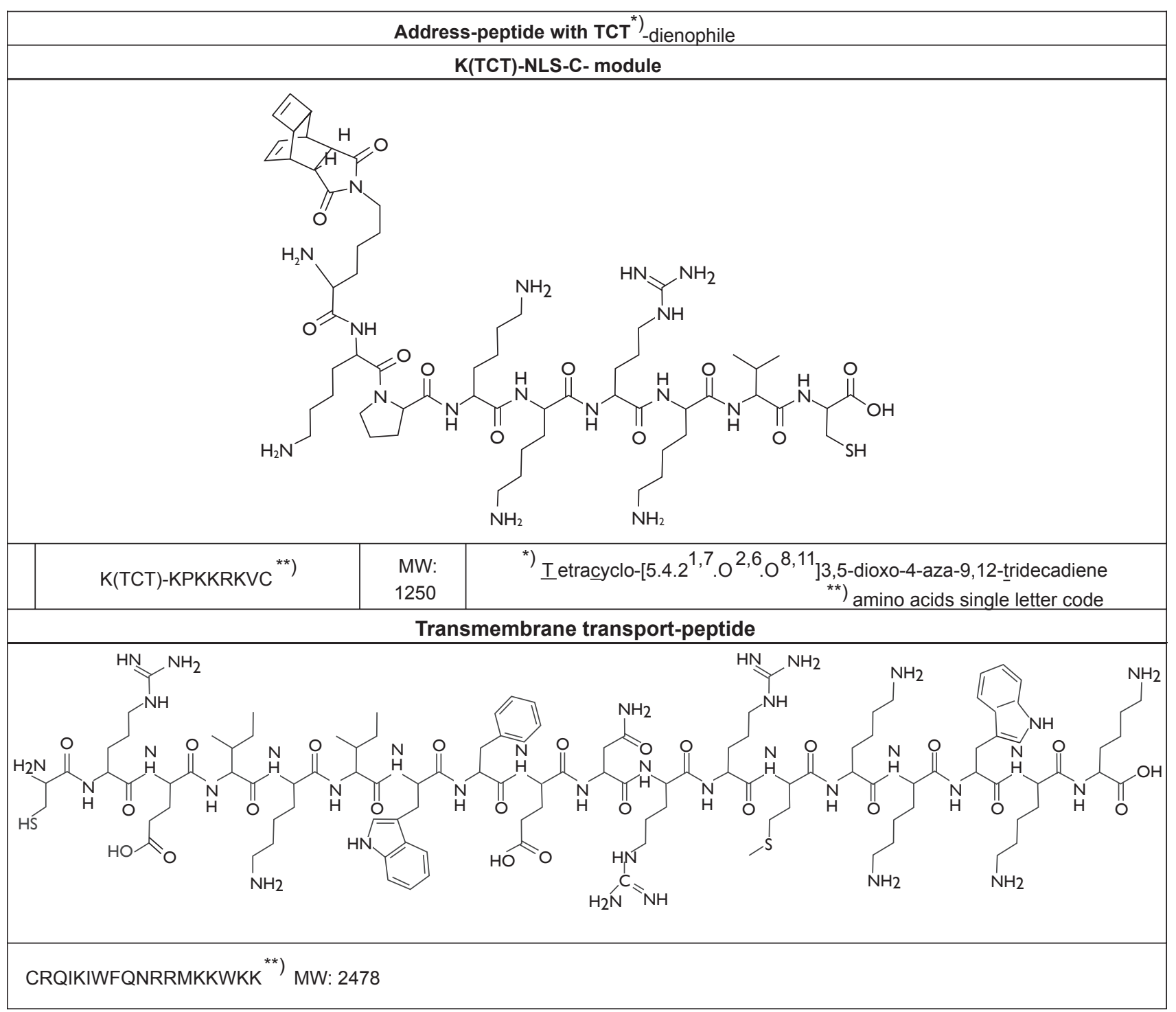

The table depicts the transmembrane transport module (lower part of the table) and the nuclear localization sequence (NLS) connected with the modified dienophile component tetracyclo-[5.4.21,7.02,6.08, II]3,5-dioxo-4-aza-9, I2-trideca-diene (TCT) via the $\varepsilon$-amino coupling of the lysine (upper part of the table).

Because the bimodal radiochemotherapy with TMZ is classified as a standard treatment approach after primary diagnosis, we focused primarily on improving the established pharmaceutical TMZ by coupling it to the modular structured carrier, termed here as the TMZ-BioShuttle, and by testing its dramatically increased efficiency in different glioblastoma cell lines.

\section{Experimental}

All reactions and procedures were carried out under normal atmospheric conditions. Table 1 shows the schematic modules, Table 2 the educts, the intermediates and the products, and Table 3 the active substances investigated.

\section{Solid phase peptide synthesis

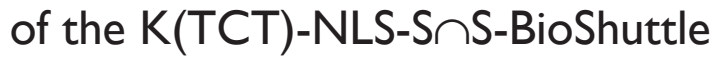 transporter}

Syntheses of the transport module and the NLS module linked with lysine (TCT)

For solid phase synthesis of the K(TCT)-NLS-S $\cap S$-transport peptide we employed the Fmoc-strategy in a fully automated multiple synthesizer (Syro II) (Merriefield 1963). The synthesis 


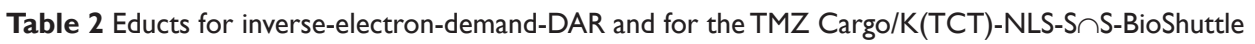

\begin{tabular}{|c|c|c|c|}
\hline $\begin{array}{c}\text { TMZ-Cargo with Diene- } \\
\text { Tetrazin-Spacer }\end{array}$ & $\begin{array}{c}\text { Address-peptide with } \\
\text { dienophile }\end{array}$ & $\begin{array}{c}\text { Cleav. } \\
\text { spacer }\end{array}$ & $\begin{array}{c}\text { Transmembrane } \\
\text { transport-peptide }\end{array}$ \\
\hline & & & \\
\hline
\end{tabular}

The left part of the table shows the amide-group modified temozolomide connected by epsilon-amino lysine to a tetrazine which acts as dien component.

Table 3 Chemical structures of the investigated active alkyla ting substances

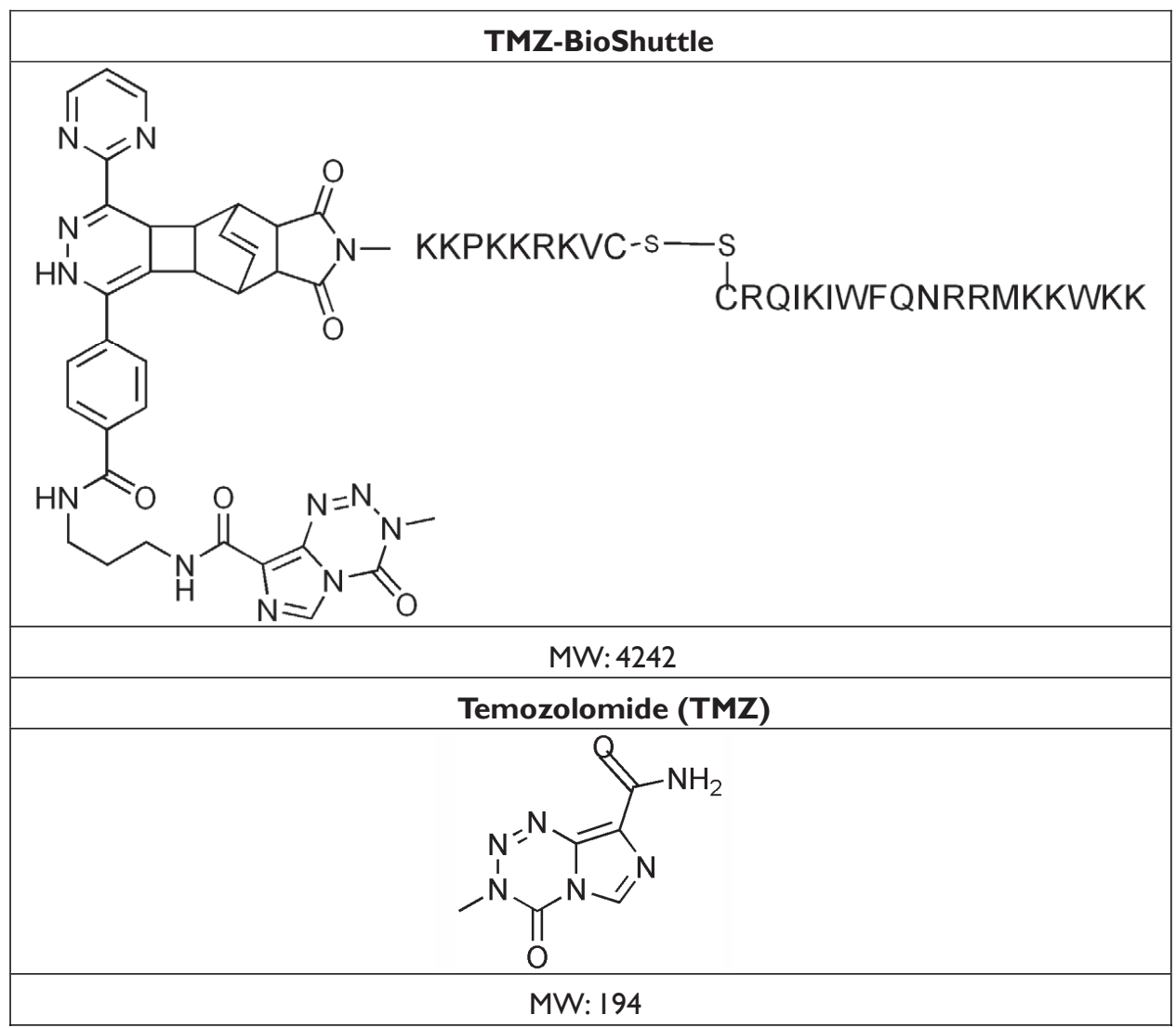

The chemical structure of the TMZ-BioShuttle is shown in the upper part of the table. The lower part shows the graphic formula of the alkylating agent temozolomide. 
was carried out on a 0.05 mmol Fmoc-Lys(Boc)-polystyrene resin $1 \%$ crosslinked and on a $0.053 \mathrm{mmol}$ Fmoc-Cys(Trt)polystyrene resin (1\% crosslinked). 2-(1H-Benzotriazole1-yl)-1,1,3,3-tetramethyluronium hexafluorophosphate (HBTU) was used as coupling agent. The last amino acid of the NLS-peptide was incorporated as Boc-Lys(TCT)-OH. Cleavage and deprotection of the peptide resin were achieved by treatment with $90 \%$ trifluoroacetic acid, $5 \%$ ethanedithiol, $2.5 \%$ thioanisol, and $2.5 \%$ phenol $(\mathrm{v} / \mathrm{v} / \mathrm{v} / \mathrm{v})$ for $2.5 \mathrm{~h}$ at room temperature. The products were precipitated in ether. The crude material was purified by preparative HPLC on an Kromasil 300-5C18 reverse phase column $(20 \times 150 \mathrm{~mm})$ using an eluent of $0.1 \%$ trifluoroacetic acid in water (A) and $60 \%$ acetonitrile in water $(\mathrm{B})$. The peptides were eluted with a successive linear gradient of $25 \%$ B to $60 \% \mathrm{~B}$ in $40 \mathrm{~min}$ at a flow rate of $20 \mathrm{~mL} / \mathrm{min}$. The fractions corresponding to the purified protein were lyophilized.

\section{Coupling of the transmembrane transporter-} and the K(TCT)-NLS-C-modules

As a last step the K(TCT)-NLS-C and the transport peptide were oxidized in an aqueous solution of $2 \mathrm{mg} / \mathrm{mL}$ in $20 \%$ DMSO for about 5 hours. The oxidation progress was monitored by analytical C18 reversed-phase HPLC, and then peptide was purified as described above. The purified material was characterized with analytical HPLC and laser desorption mass spectrometry in a Bruker Reflex II.

The empirical formula of the $\mathrm{K}$ (TCT)-NLS-C module is C64H110N18O12S with a MW 1355,74.

\section{Ligation chemistry of the K(TCT)-NLS- SnS-BioShuttle and the TMZ-derivative TMZ- $_{\text {(amino-bond) }}$-tetrazolin-spacer linkage} with the BioShuttle-carrier

A $0.2 \mathrm{~mol}$ preparation with $42.7 \mathrm{mg} \mathrm{L1834}$ and $67.4 \mathrm{mg}$ L1932 as well as $28 \mu \mathrm{L}$ triethylamin were dissolved in chloroform. The reaction process runs undisturbed and provides a defined product with the molecular weight (MW) m/e 513. Further preparation: $0.3 \mathrm{mmol}$ L1932 Triflat MW 445 and $0.4 \mathrm{mmol}$ L1834 were dissolved in $100 \mu \mathrm{L}$ triethylamin $0.7 \mathrm{mmol}$ overnight at room temperature. Thin-layer chromatography (TLC) (9.5/0.5 chloroform/EtOH) indicates a defined product which points to the complete reaction.

TMZ-dien-spacer linked with K(TCT)-NLS-SnS-BioShuttle Preparation of $0.2 \mathrm{mmol}$ (48 $\mathrm{mg}$ F77 and $44 \mathrm{mg}$ L1834) with $0.2 \mathrm{mmol}(0.03 \mathrm{~mL})$ triethylamin: After dissolving the F77 in triethylamin and chloroform, the acid chloride of L1834 was added. The chemical reaction was carried out overnight at room temperature and the product was detected by TLC.

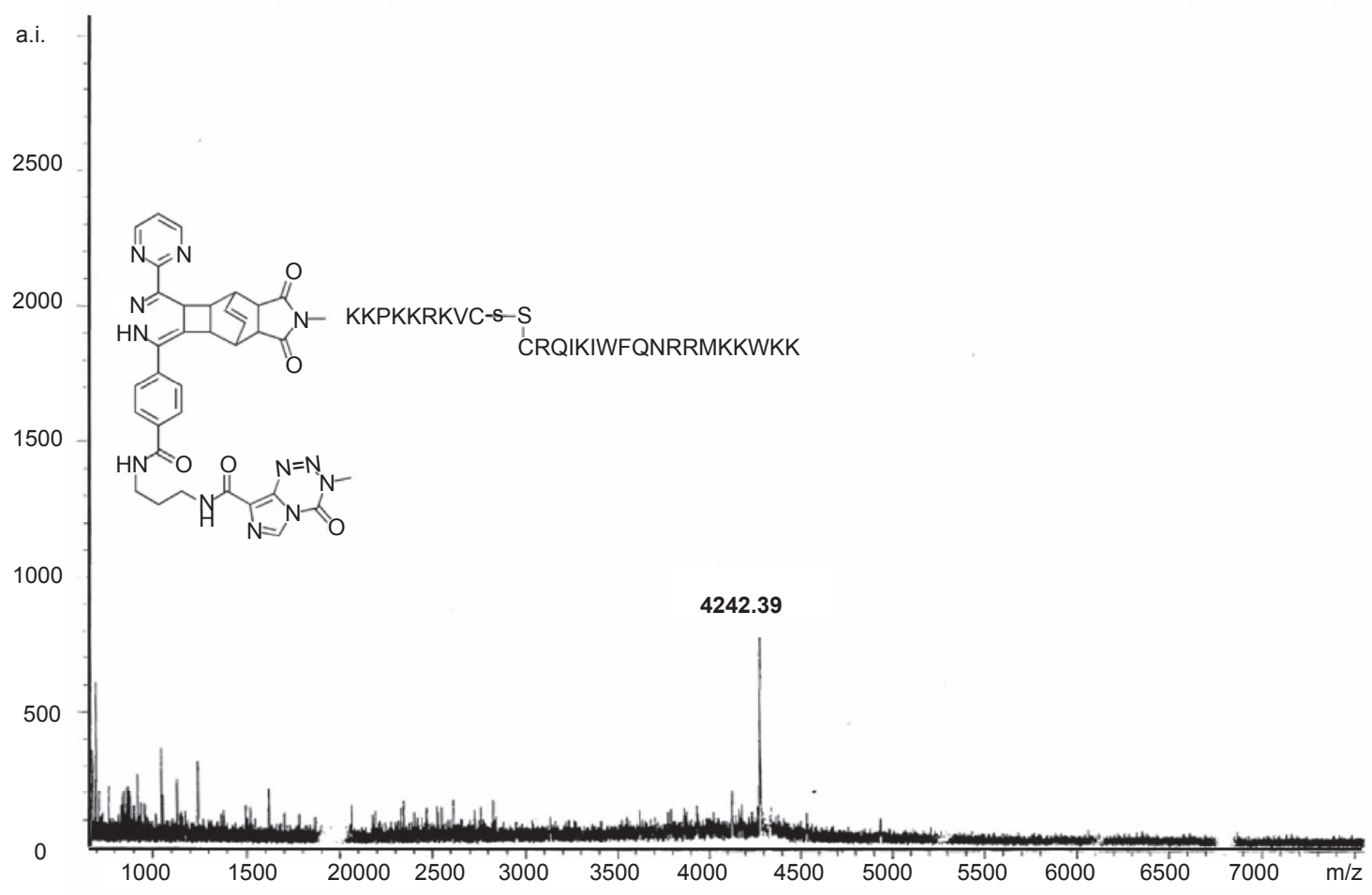

Figure I Mass spectrometry plot of the TMZ-BioShuttle (as shown in Table 3) demonstrates the estimated molecular mass. The ordinate represents the absolute intensity (a.i.); the abscissa the mass to charge ratio $(\mathrm{m} / \mathrm{z})$. 
By mass spectrometry we detected the mass of the chemical compound 4242.

\section{Reagents and cell culture}

Human glioblastoma (GBM) primary cells (Glio98 and Glio366) were provided by the DKFZ division of Biophysics of Macromolecules. All cell lines were cultured in DMEM (Gibco Cat. No. 12800) supplemented with 10\% FCS and maintained in culture at $37^{\circ} \mathrm{C}$ with $5 \% \mathrm{CO}_{2}$ atmosphere and 95\% humidity.

\section{Chemotherapy treatment}

Pure temozolomide (TMZ) was purchased from SigmaAldrich, Germany (Cat. No. 76899) and the material was subdivided into two parts for subsequent processing. One part was followed up and coupled to the transporter molecules. As a control, the second part was dissolved in acetonitrile $10 \%$ (Sigma-Aldrich, Germany) with a final concentration of $0.2 \%$ acetonitrile. Further control studies with acetonitrile were performed to exclude potential toxic effects of acetonitrile.

Glio98 and Glio366 cells were suspended $\left(1 \times 10^{5}\right.$ cells $\left./ \mathrm{mL}\right)$ in DMEM (control) and in DMEM containing appropriate amounts of TMZ and the TMZ-BioShuttle ( $50 \mu \mathrm{M}$ equimolar) and cell behavior was investigated for up to 6 days of induction time.

\section{Cell cycle and cell death analysis}

The effects on cell viability and cell cycle distribution were determined by DNA flow cytometry. Flow cytometric analyses were performed using a PAS II flow cytometer (Partec, Muenster, Germany) equipped with a mercury vapor lamp (100 W) and a filter combination for 2,4-diamidino-2-phenylindole (DAPI) stained single cells. From native probes the cells were isolated with $2.1 \%$ citric acid $/ 0.5 \%$ Tween 20 according to the method for high resolution DNA and cell cycle analyses (Ehemann et al 2003) at room temperature with slight shaking. Phosphate buffer $\left(7.2 \mathrm{~g} \mathrm{Na}_{2} \mathrm{HPO} 4 \times 2 \mathrm{H}_{2} \mathrm{O}\right.$ in $100 \mathrm{~mL}$ $\mathrm{H}_{2} \mathrm{O}$ dest.) $\mathrm{pH} 8.0$ containing DAPI was used for staining the cell suspension. Each histogram represents 30,000 cells for measuring DNA-index and cell cycle. For histogram analysis, we used the Multicycle program (Phoenix Flow Systems, San Diego, CA).

Cell viability - assessed by flow cytometry

with the Pl-method

For detection of apoptotic cells and viability, a FACS Calibur flow cytometer (Becton Dickinson Cytometry Systems, San Jose, CA) was used with filter combinations for propidium iodide. The Cellquest program (Becton Dickinson Cytometry Systems, San Jose, CA) was used for analyses and calculations. Each histogram and dot plot represents 10,000 cells. After preparation according to Nicoletti et al (1991) with modifications (Singer et al 2007; Tschaharganeh et al 2007), measurements were acquired in the logarithmic mode in F1-3 and calculated by setting gates over the first three decades to detect apoptotic cells. Dead cells are positive for propidium iodide and stained red; living cells remain unstained. In the logarithmic histogram the positions of unstained living cells are in the first 2 decades, the $3 \mathrm{rd}$ decade contains cells with membrane damage, and dead cells are placed in the 4 th decade.

\section{Results}

\section{Time-course of cell growth and cell death in Glio98 and Glio366 cells induced by TMZ and TMZ-BioShuttle - pharmacological effects}

Two different glioma cell lines, herein referred as Glio98 (Figure 2a-e, left column) and Glio366 (Figure 2a-e, right column) were used to investigate the effect of TMZ and TMZ-BioShuttle on brain tumor cells. After 24 hours of treatment with the TMZ-BioShuttle, no change in the phenotype of both glioma cell lines could be observed under the light microscope (data not shown); however in the cell culture medium an increasing number of aggregated cells could be observed. In our opinion after 72 hours of treatment with TMZ cells a possible reconstitution of the phenotype was shown and also a regrowth 144 hours after TMZ treatment (Figure 2e). The cells treated with the TMZ-BioShuttle seemed not to regenerate.

After 144 hours of treatment with the TMZ-Bioshuttle an increase of aggregated Glio366 cells and of smaller scale aggregations in Glio98 cells in the cell culture medium were observed (not visible in the picture). Both adherent cells types reveal a non-confluent state because of many dead cells in the TMZ-treated probes. The cell density declines dramatically from 72 to 144 hours after TMZ-BioShuttle treatment in both glioma lines but the decrease of adherent cells was greater in Glio366 cells than in Glio98 cells (Figure 2c).

To learn more about the cell death in the two treated glioma cells after treatment, we carried out comet assays in parallel probes (compared to Figure 2). Basically the Glio98 and Glio366 cells did not exhibit fragmented DNA; no comets of the Glio98 cells 72 hours after treatment with TMZ (Figure 3d) and TMZ-BioShuttle (Figure 3b) can be 

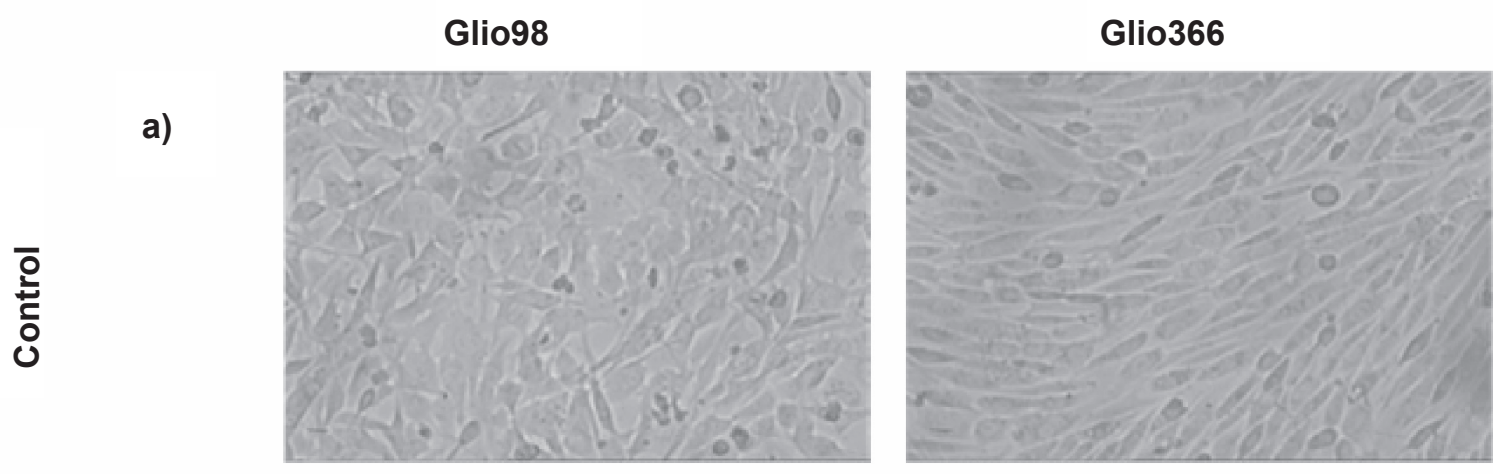

b)
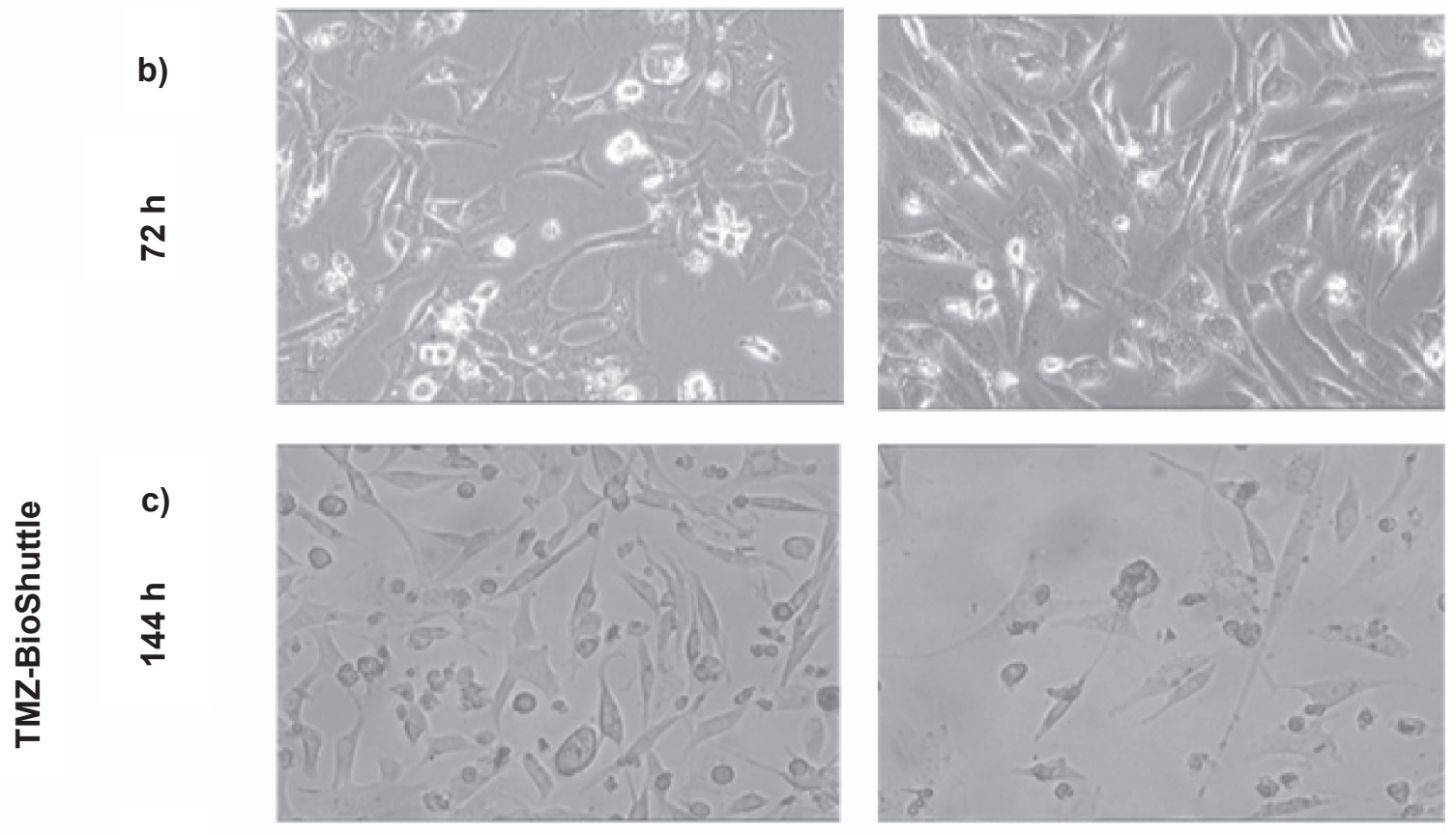

d)
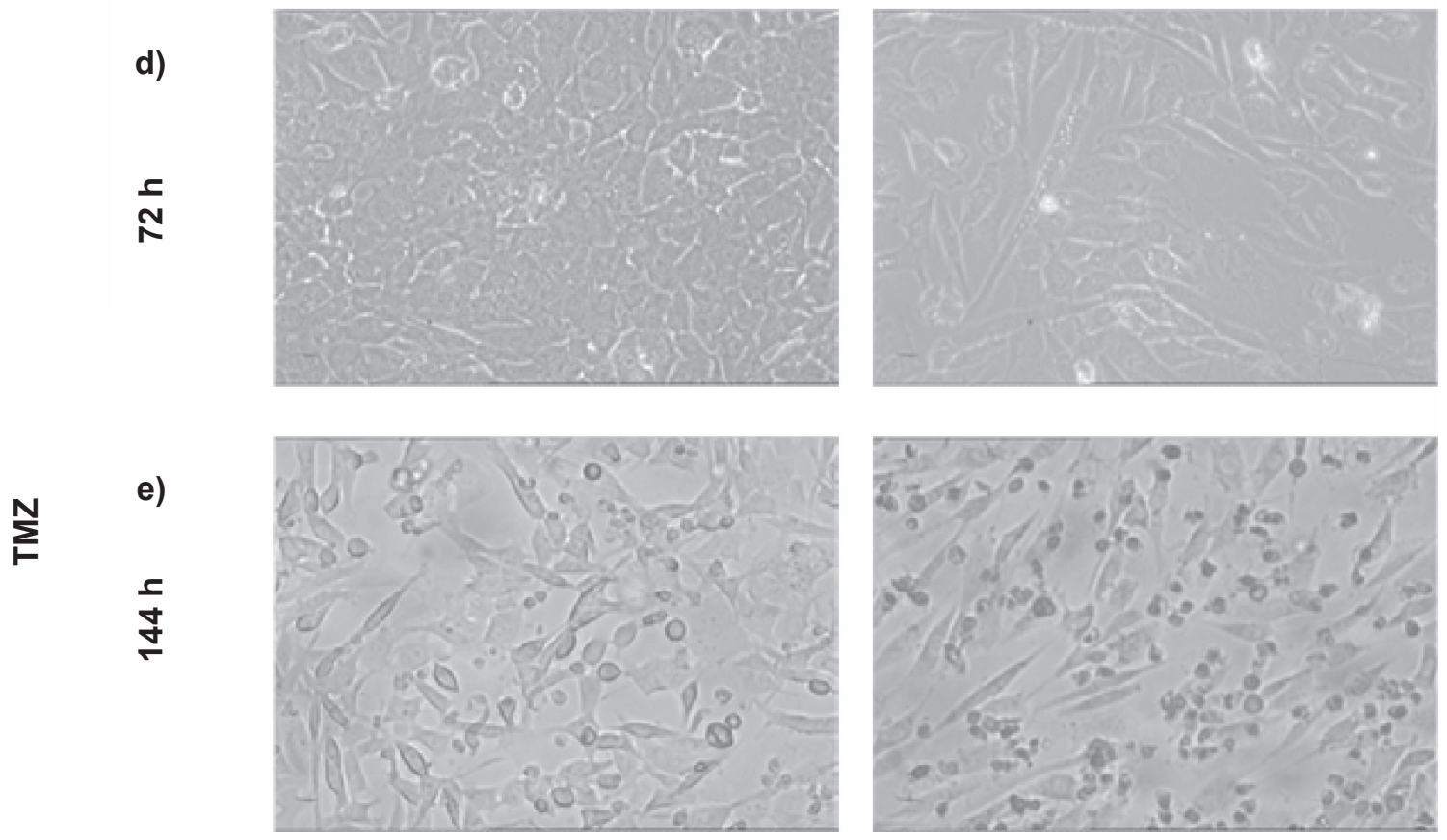

Figures 2a-e Microscopical monitoring of the treated glioblastoma cells. 
observed and they resembled the untreated Glio control cells (Figures $3 \mathrm{a}$ in both cell lines).

After 144 hours of treatment with TMZ (Figure 3e) the glioblastoma cells show different-sized and fragmented dead cells and comet structures. The shape of the two observed comets was not used for calculation since it was not a major event. The TMZ-BioShuttle treated cells are mainly swollen (Figure 3c). Furthermore, the total cell density of the TMZ-only treated samples was lower, compared with that in control and TMZ-BioShuttle treated samples. The comet assay study detected no DNA fragmentation in the Glio98 and the Glio366 until 72 hours after treatment. 144 hours after application of TMZ-BioShuttle large amounts of cell fragments could be observed in all treated cell lines (Figure $3 \mathrm{c}$ ). DNA fragments could be detected in Glio366 (Figure 3e right column) but comets in the Glio98 cells are not visible 144 hours after TMZ treatment (Figure 3e left column).

\section{Cell cycle study}

As can be seen in the next experiment the predominant event was discovered in the cell cycle investigation. Flow cytometry is considered to be a valuable tool for high throughput measurements of the cell cycle, cellular dynamics, cell activities and cell toxicity studies. It provides sensitive and specific data on the cellular behavior of glioblastoma cells after treatment with TMZ and the TMZ-BioShuttle conjugate. We determined the cell cycle behavior of glioma cells, for example, of the Glio366 cells after drug treatment. To investigate the influence of TMZ with and without BioShuttle transporter we performed a time-course analysis of the cell cycle. Cell growth after drug treatment was dramatically different. The pharmacological effect on brain tumor cells was shown 144 hours after treatment with TMZ-BioShuttle.

Figure 4 shows cell cycle distribution of Glio366 cells 144 hours after treatment: The plots named control, TMZBioShuttle, and TMZ are shown from left to right. The cell cycle distribution is indicated as G1-phase, S-phase and the G2/M phase. These cells show a diploid cycle (red colored). The plot of the untreated control is shown (Figure 4, left) and exhibits a G1 cell fraction of 79\% and a G2 cell fraction of $10 \%$. The contingent of cells in the S-phase amounts to $11 \%$. Compared to the S-phase fraction of untreated control the percentage of S-phase cells treated with TMZ is decreased to $8 \%$. The TMZ-BioShuttle treated Glio366 cells clearly exhibit a decreased amount of cells in the S-phase (2\%). Compared to control, the TMZ and the TMZ-BioShuttle treated probes display an increased cell number in the $\mathrm{G} 2 / \mathrm{M}$ phase of $20 \%$ and $72 \%$, respectively. The cells in the G1-phase of the
TMZ probe decreased slightly (72\%) whereas in cells in the G1-phase of the TMZ-BioShuttle treated Glio366 cells decreased significantly $(26 \%)$ as shown in Table 4 . The amount of debris (blue colored) is visible and each histogram represents 30,000 measured cells.

\section{Cell viability study on human Glio98 Glio366 cells}

The cell killing effect of TMZ and the TMZ-BioShuttle on the glioblastoma cell lines Glio98 and Glio366 is demonstrated in Figure 5 and in the corresponding values implemented in the Table 5.

The pharmacological effect of the TMZ-BioShuttle on Glio366 and Glio98 cells differs greatly from that of the non-derivatized TMZ.

The cell lines show a different sensitivity to chemotherapy with TMZ and TMZ-BioShuttle respectively. After 72 hours of treatment with TMZ-BioShuttle, $28 \%$ of Glio366 cells were dead; after 144 hours of TMZ-BioShuttle treatment $32.5 \%$ of the Glio366 cells were dead. The effect of TMZ on the Glio366 cell line was less noticeable compared to control. Dead cells at 72 hours after TMZ treatment are in the range of untreated controls (Glio366: 4.5\% increases to $7 \%$ ) after 6 days. The percentage of dead cells after TMZ treatment was decreased slightly (by 3.5\%). 144 hours after TMZ treatment no difference was detectable between percentage of dead control cells and treated cells (7.5\%). The percentage of dead cells is an underestimation because many cells were already degraded (Figure 2c).

The sensitivity of the investigated Glio98 cells to TMZ and TMZ-BioShuttle is somewhat different from that of Glio366 cells. Percentage of dead Glio98 control cells increased from $2.5 \%$ (3 days) to $10.5 \%$ (6 days). Three days after TMZ treatment, the relative amount of dead cells barely differed from the corresponding control cells (3.5\%). Six days after TMZ treatment the amount of dead cells increased to $14.5 \%$. After 3 days of TMZ-BioShuttle treatment Glio98 cells exhibit $13.5 \%$ dead cells, and $22 \%$ after 6 days of treatment.

\section{Discussion}

Treatment of high-grade gliomas poses a substantial challenge to neuro-oncologists. The main problems are positions of the tumors in the cerebrum, which allow a radical excision only in a limited number of patients, and a high recurrence rate after excision. Current available chemotherapy (nitrosoureas, procarbazine and vincristine or the PCV protocol) is now at least 25 years old and even when combined with radiotherapy has not changed the fatal prognosis for patients 


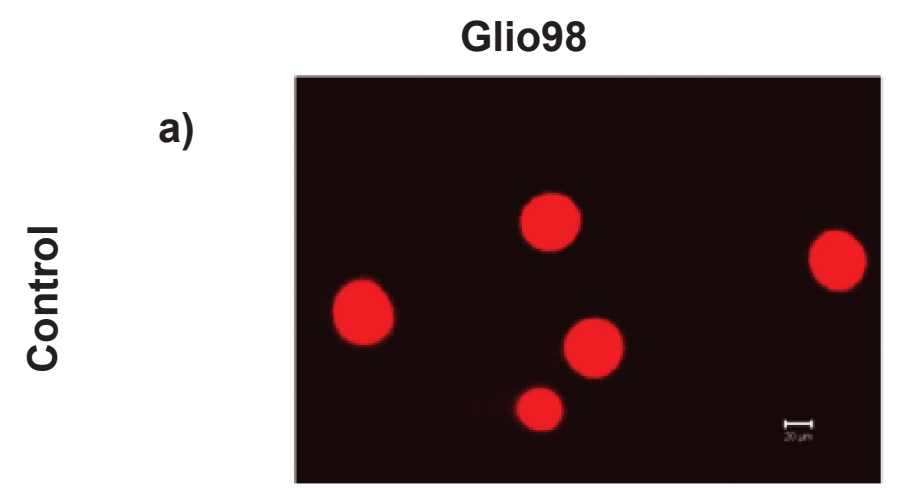

\section{Glio366}

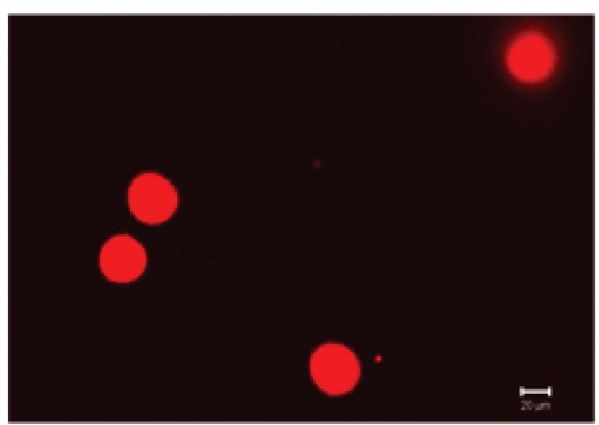

b)
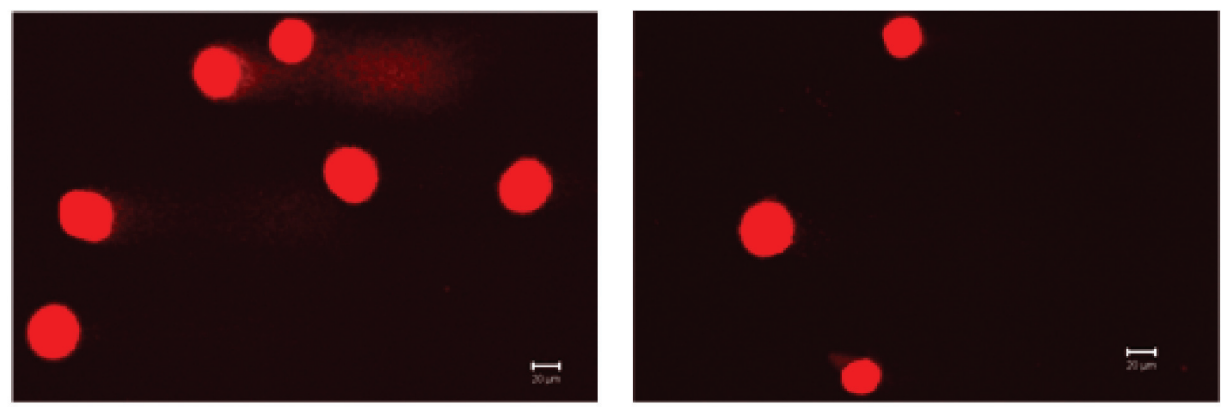

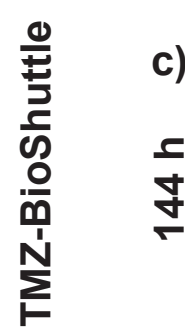
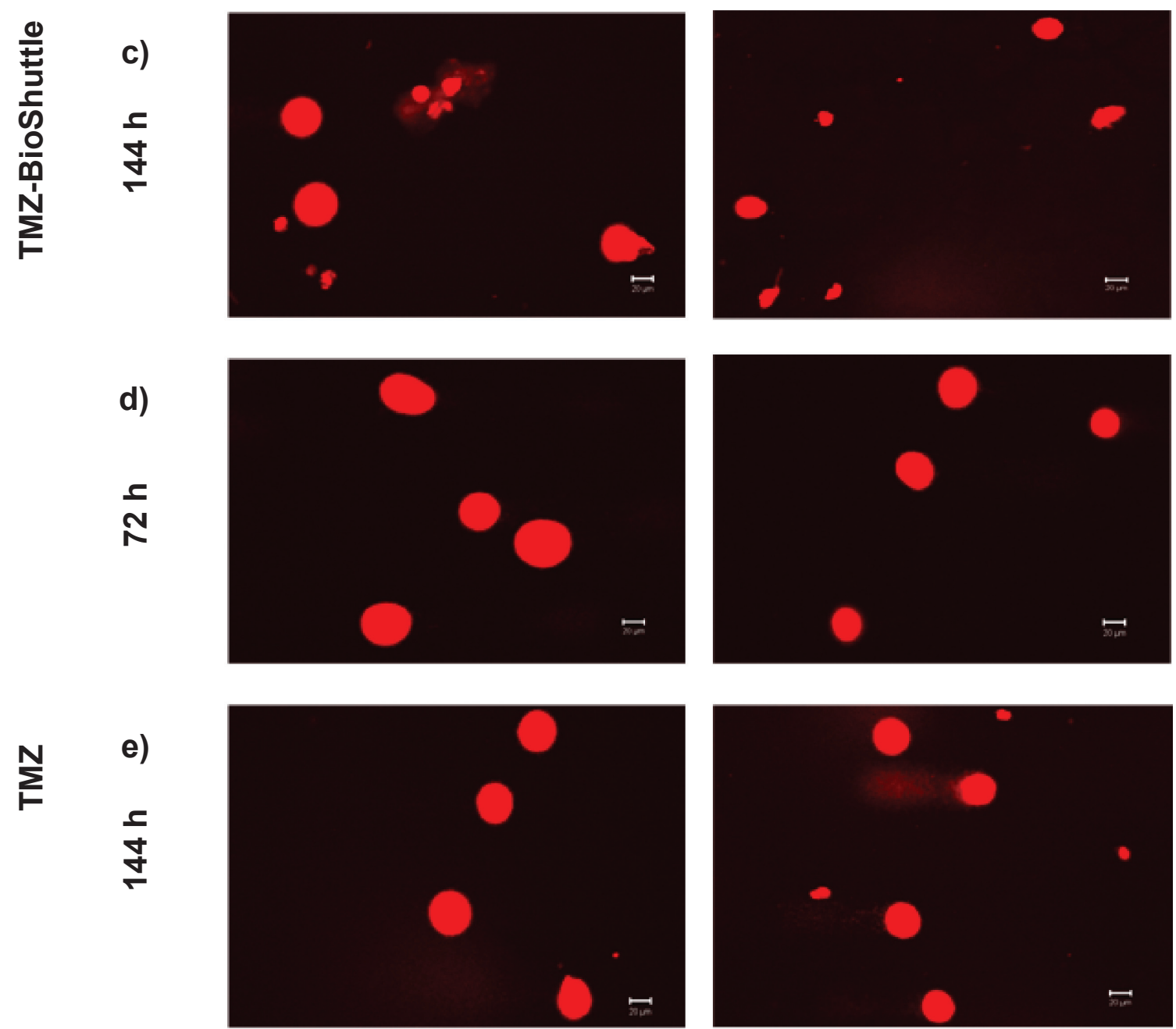

e)
$\frac{f}{2}$

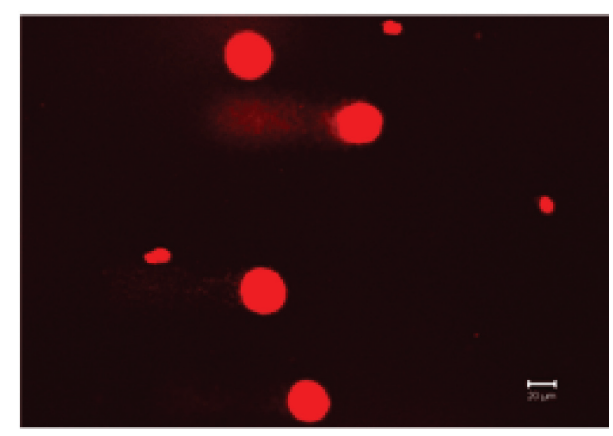

Figure 3a-e Comet assay studies of untreated cells, treated with TMZ and TMZ-BioShuttle for different cell lines; the scale bar represents $20 \mu \mathrm{m}$. 


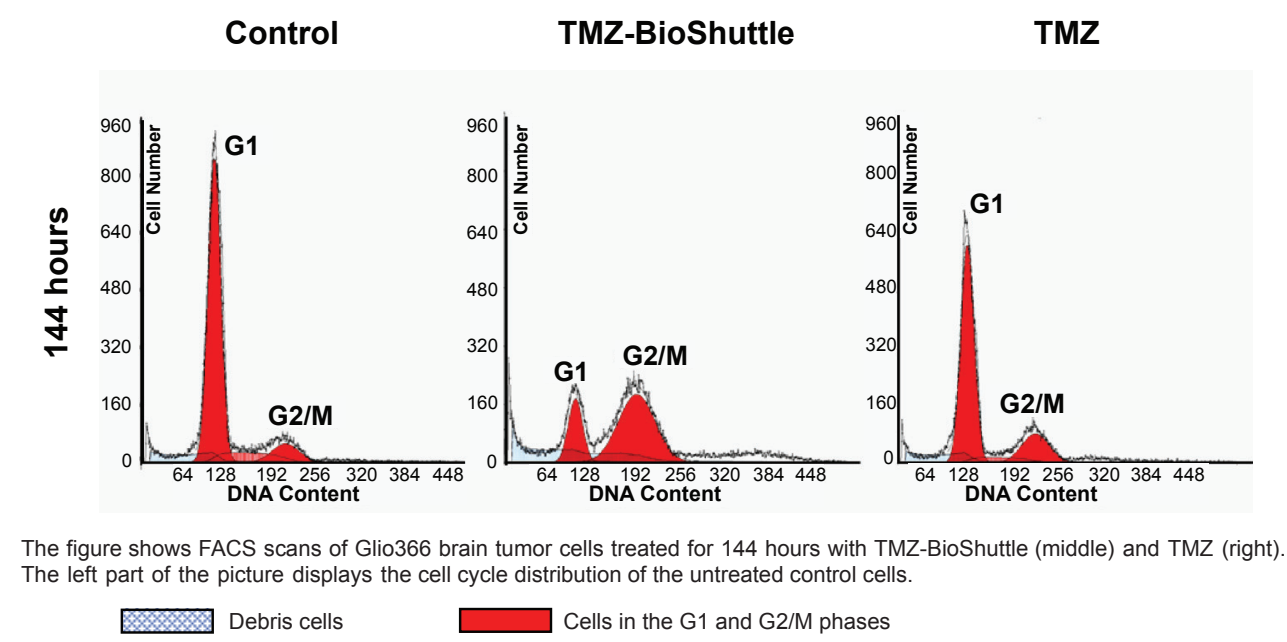

Figure 4 Cell cycle of Glio366 cells after application of TMZ and TMZ-BioShuttle.

The figure shows FACS scans of Glio366 brain tumor cells treated for 144 hours with TMZ-BioShuttle (middle) and TMZ (right). The left part of the picture displays the cell cycle distribution of the untreated control cells.

Debris cells Cells in the GI and G2/M phases.

with high-grade glioma; also, progression-free survival in patients with glioblastoma multiforme has been greatly improved. Therefore, the initial reports of a substantial antitumor activity of temozolomide (TMZ) in brain tumors demonstrated by Newlands et al could indicate a relief (Newlands et al 1992). TMZ, a DNA-methylating agent of the imidazotetrazine class, was developed in the 1980s, through rational drug design (Denny et al 1994; Newlands et al 1997).

With regard to undesired side-effects like the oftenobserved strong suppression of the peripheric lymphocytes, the connection of the 'old fashioned' TMZ drug as a cargo to transporter molecules (TMZ-BioShuttle) was investigated. These peptides, designed for facilitating rapid transport across cellular membranes, could improve their delivery and their targeting under the pharmacological activity in cells and tissues protecting cells in the bloodstream.

The treatment of glioblastoma Glio366 cells with TMZ interferes with the cell cycle and results in a decreased number of cells in the S-phase fraction as shown 144 hours after TMZ application (11\% in the control and $8 \%$ in the TMZ treated cells). Furthermore, in the TMZ-BioShuttle treated cells the smallest contingent of the S-phase cells of $2 \%$ was detectable (Figure 4 and Table 4 ) after 144 hours.

The fact that the glioblastoma cells arrest in the G2/Mphase after TMZ-treatment was documented by Hirose et al (2003) and could be not be confirmed by the tested Glio366 cells, but the treatment with TMZ-BioShuttle clearly increased cell number residing in the G2/M-phase by up to $72 \%$. The increase seems to be attributable to interactions of TMZ and TMZ-BioShuttle with the mitogen-activated protein (MAP) kinase p38 $\alpha$, which is activated by the mismatch repair system (MMR) and is responsible for the TMZ-induced G2/M block (Hirose et al 2003).

The phenomenon of a slightly reduced S-phase ( $8 \%$ versus control $11 \%$ ) in the TMZ treated Glio366 cells is not contradictory to the common effects of alkylating agents which retard rate of cell division (Bignold 2006). A possible explanation for the strongly decreased S-phase cell number in the TMZ-BioShuttle treated probes would be the existence of a S-phase cell cycle arrest as documented in a bimodal TMZ/ interferon- $\beta$ (IFN- $\beta$ ) study (Park et al 2006). Our flow cytometry experiments also showed a strong cell cycle arrest in the S-phase (Thomas et al 1996). A further criterion for a prolonged late S/G2-phase suggests an implication of the histone acetyltransferase 1 (HAT1) which participates in recovering block-mediated DNA damage (Barman et al 2006).

Table 4 Relative amount of cells in the cell cycle 72 and I 44 hours after TMZ and TMZ-BioShuttle treatment

\begin{tabular}{|c|c|c|c|c|}
\hline & Cell fraction & Control & TMZ-BioShuttle & TMZ \\
\hline$\cong$ & GI [\%] & 73 & 33 & 74 \\
\hline 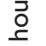 & G2 [\%] & 19 & 17 & 16 \\
\hline i & S [\%] & 8 & 50 & 10 \\
\hline$\cong$ & GI [\%] & 79 & 26 & 72 \\
\hline כ. & G2 [\%] & 10 & 72 & 20 \\
\hline$\dot{z}$ & $\mathrm{~S}[\%]$ & 11 & 2 & 8 \\
\hline
\end{tabular}

The table is derived from the FACS scan data and shows an overview of the cell cycle distribution of Figure 5 calculated as a percentage. 

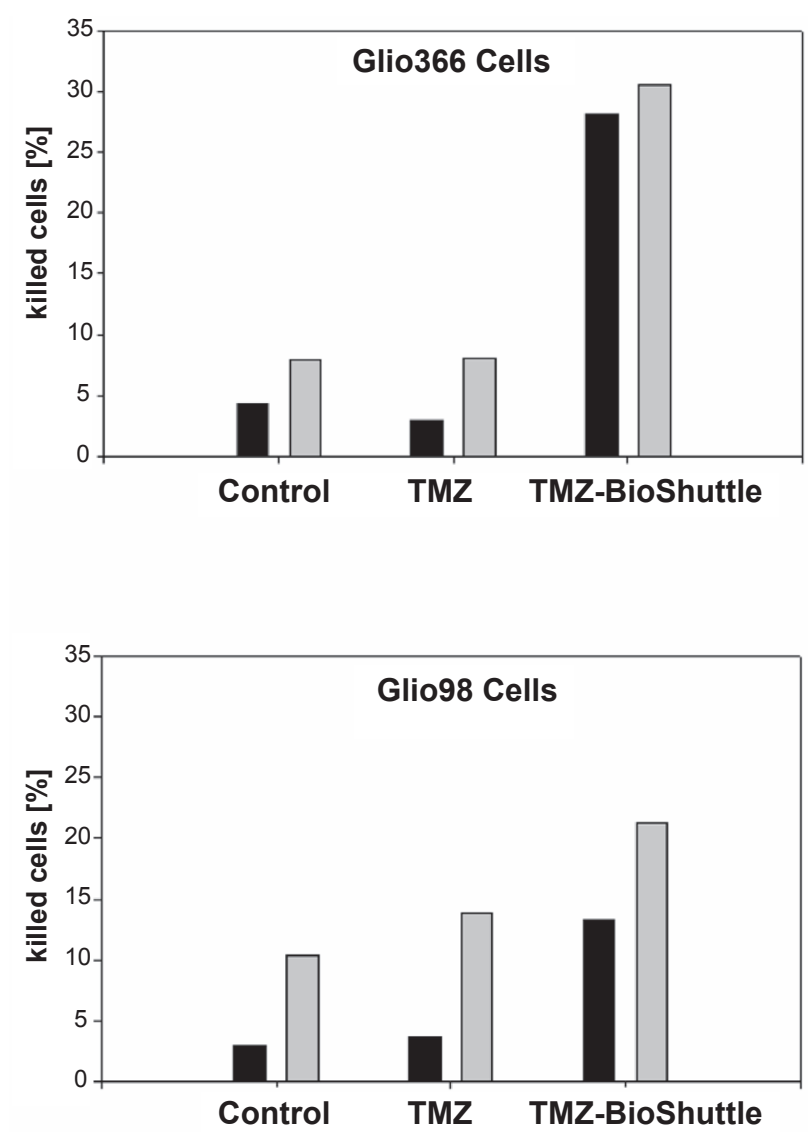

Figure 5 Flow cytometric estimation of cell killing of Glio366 (upper part) and of Glio98 cells (lower part. The abscissae of the graph show the relative amount of the dead Glio366 cells after 72 hours (black bars) and after 144 hours (gray bars) after exposure to the TMZ-BioShuttle (right bar-pair).The bars at the left site indicate the untreated control cells and the bar pair in the middle, the dead cells, TMZ-treated. The ordinates represent the relative amount of dead cells (\%).

After exposure to the TMZ-BioShuttle for 144 hours, the observed strong increase of the G2-phase cells of Glio366 cells could possibly originate from the documented inhibition of the RNA and protein syntheses, which are necessary for the successful completion of G2 and the initiation of mitosis. These G2-arrested cells were found to be deficient in certain proteins that may be specific for the G2-mitotic transition (Rao 1980). Obstruction of the cell cycle process results in the decrease of the G1-phase cell fraction (26\%) of the TMZ-BioShuttle treated Glio366 cells, which appears to be a consequence of their disability passing in the mitotic process.

The fact that TMZ is also known to induce a transient proliferation arrest combined with the accumulation of cells in the G2/M phase could be confirmed as shown in the decrease of the cells in the S-phase and in turn by the increase of cells in the G2/M-phase from $10 \%$ (control) to $20 \%$. In parallel a decrease of the G1-phase cells (72\%) compared to the control (79\%) could be observed also in the Glio366 after 6 days. The conditioning to the cell cycle of the untreated control cells and cells 6 days after TMZ application could be a process described as potentially dependent on the p53 status (Hirose et al 2001). It is documented that in glioma, p53 wild-type cells undergo prolonged cell cycle arrest associated with elevation of p53 levels, and although the cells are non-proliferative, they remain viable. Conversely, p53-deficient cells undergo a more transient cell cycle arrest and within 12 days lose viability by mitotic catastrophe and/or apoptosis. Preclinical models demonstrated a schedule-dependent antitumor activity against high-grade glioma, suggesting increased activity with repeated exposure to TMZ (Raymond et al 1997).

Further, the activity of the $\mathrm{O}^{6}$-methylguanine-DNAmethyltransferase (MGMT) is involved in the DNA-repairprocedures in cells. The epigenetic silencing of the MGMT DNA-repair gene is associated with longer survival in glioblastoma patients and benefits from alkylating agents like TMZ (Hegi et al 2005). Possibly after treatment, the cell cycle behavior of the Glio366 could be explained with epigenetic properties like $\mathrm{CpG}$ island hypermethylation of the DNA repair enzyme MGMT. The restricted TMZ activity and the crucial role of the repair enzyme MGMT are documented in the literature (Antoun et al 2000; Walton et al 2008). Here we did not consider to which extent the enrichment of pharmacological DNA-active methylating substances like TMZ could contribute to overcoming the opposite effects. If and to what extent MGMT effects are involved remains to be seen in further studies.

Figure 5 shows a dramatically increased sensitivity of both the Glio98 and the Glio366 cells to TMZ compared

Table 5 Relative amount of dead Glio366 and Glio98 cells [\%]

\begin{tabular}{|c|c|c|c|c|c|c|}
\hline & \multicolumn{3}{|c|}{ After 72 hours } & \multicolumn{3}{|c|}{ After I 44 hours } \\
\hline & control & TMZ & TMZ-BioShuttle & control & TMZ & TMZ-BioShuttle \\
\hline Glio366 & 4.5 & 3.5 & 28 & 7.5 & 7.5 & 32.5 \\
\hline Glio98 & 2.5 & 3.5 & 13.5 & 10.5 & 14.5 & 22 \\
\hline
\end{tabular}

Actual amount of killed cells derived from Figure 5 . 
with the TMZ-BioShuttle. The present data document a different cellular contumaciousness to TMZ treatment. A real effectiveness of the pure TMZ in Glio366 and Glio98 cells could not be observed, whereas clear cell killing effects caused by TMZ-BioShuttle were detected in contrast.

It is important to note that the TMZ-BioShuttle treatment of Glio366 and Glio98 glioma cells redounds to cell killing effects as shown in Figure 5 and Table 5. In the TMZ treated Glio366 probes dead cells barely differered from their ratio in the untreated cells after 3 days $(3 \%-4 \%)$ as well as after 6 days (9\%) after TMZ application, but the percentage of dead cells treated with TMZ-BioShuttle escalated to $28 \%$ after 3 days and $32.5 \%$ after 6 days.

Furthermore the novel properties of the TMZ-BioShuttle could give reason to the enlargement of other tumor entities like the therapy of prostate tumors.

The application of the TMZ-BioShuttle could minimize the handicap of TMZ for the therapy of patients with brain tumors but the establishment of the TMZ-BioShuttle necessitates new ways for the synthesis. Conditions that hampered the above postulated criteria such as rapid and whole concurrent chemical reactions in aqueous solution at room temperature for a proper chemical ligation of functional peptides could be circumvented using the 'inverse-electrondemand' of the Diels-Alder reaction. This reaction enhances the economics of the chemical reaction by the following parameters: the increase in the reaction rate, gentle reaction conditions at room temperature and the resulting reaction kinetics demand no excess at all in the educts. Furthermore this careful execution of the chemical reaction could realize the ligation of pharmacologically active but sensitive and highly unstable pharmaceutical ingredients without functional deprivation. The potential of the TMZ modified by coupling to the BioShuttle carrier (TMZ-BioShuttle) has been confirmed for the treatment of brain tumors and remains an attractive drug for further clinical combination chemotherapy.

\section{Dedication}

This article is dedicated to Harald zur Hausen, the winner of the Nobel Price Award 2008 in Medical Sciences, and the retired Head of the German Cancer Research Center.

\section{Acknowledgments}

The work in this article was done in close collaboration with other members of our group. We cordially thank Dr Christian Kliem and Dr Jochen vom Brocke for technical assistance.

\section{Abbreviations}

DAR, Diels-Alder-reverse; GBM, glioblastoma multiforme; MGMT, methylguanine-DNA-methyltransferase; NLS, nuclear localization sequence; TCT, tetracyclo-[5.4.2 $2^{1,7}$. $\left.\mathrm{O}^{2,6} . \mathrm{O}^{8,11}\right] 3,5$-dioxo-4-aza-9,12-tridecadien; TMZ, temozolomide.

\section{Disclosures}

The authors declare no conflicts of interest.

\section{References}

Advani SJ, Weichselbaum RR, Whitley RJ, et al. 2002. Friendly fire: redirecting herpes simplex virus-1 for therapeutic applications. Clin Microbiol Infect, 8:551-63.

Anthony-Cahill SJ, Magliery TJ. 2002. Expanding the natural repertoire of protein structure and function. Curr Pharm Biotechnol, 3:299-315.

Antoun G, Baylin SB, li-Osman F. 2000. DNA methyltransferase levels and altered $\mathrm{CpG}$ methylation in the total genome and in the GSTP1 gene in human glioma cells transfected with sense and antisense DNA methyltransferase cDNA. J Cell Biochem, 77:372-81.

Bachmann WE, Deno NC. 1949. The Diels-Alder Reaction of 1-vinylnaphthalene with a,@- and a,p,y,G-unsaturated acids and derivatives. J Americ Chem Soc, 71:362-3.

Bangham AD, Papahadjopoulos D. 1966. Biophysical properties of phospholipids. I. Interaction of phosphatidylserine monolayers with metal ions. Biochim Biophys Acta, 126:181-4.

Barman HK, Takami Y, Ono T, et al. 2006. Histone acetyltransferase 1 is dispensable for replication-coupled chromatin assembly but contributes to recover DNA damages created following replication blockage in vertebrate cells. Biochem Biophys Res Commun, 345:1547-57.

Bignold LP. 2006. Alkylating agents and DNA polymerases. Anticancer Res, 26:1327-36.

Bode JW, Fox RM, Baucom KD 2006. Chemo selective amide ligations by decarboxylative condensations of $\mathrm{N}$-alkylhydroxylaminesandaketoacids. Angew Chem, 118:1271-4.

Bourne N, Stanberry LR, Kern ER, et al. 2000. Dendrimers, a new class of candidate topical microbicides with activity against herpes simplex virus infection. Antimicrob Agents Chemother, 44:2471-4.

Braun K, Peschke P, Pipkorn R, et al. 2002. A biological transporter for the delivery of peptide nucleic acids (PNAs) to the nuclear compartment of living cells. $J$ Mol Biol, 318:237-43.

Camarero JA, Kwon Y, Coleman MA. 2004. Chemoselective attachment of biologically active proteins to surfaces by expressed protein ligation and its application for "protein chip" fabrication. J Am Chem Soc, 126:14730-31.

Chandra RA, Douglas ES, Mathies RA, et al. 2006. Programmable cell adhesion encoded by DNA hybridization. Angew Chem Int Ed Engl, 45:896-901.

Combs SE, Gutwein S, Schulz-Ertner D, et al. 2005. Temozolomide combined with irradiation as postoperative treatment of primary glioblastoma multiforme phase I/II study. Strahlenther Onkol, 181:372-7.

Conlon TJ, Flotte TR. 2004. Recombinant adeno-associated virus vectors for gene therapy. Expert Opin Biol Ther, 4:1093-101.

Denny BJ, Wheelhouse RT, Stevens MF, et al. 1994. NMR and molecular modeling investigation of the mechanism of activation of the antitumor drug temozolomide and its interaction with DNA. Biochemistry, 33:9045-51.

Derossi D, Calvet S, Trembleau A, et al. 1996. Cell internalization of the third helix of the Antennapedia homeodomain is receptor-independent. J Biol Chem, 271:18188-93.

Ehemann V, Sykora J, Vera-Delgado J, et al. 2003. Flow cytometric detection of spontaneous apoptosis in human breast cancer using the TUNEL-technique. Cancer Lett, 194:125-31. 
Heckl S, Debus J, Jenne J, et al. 2002. CNN-Gd(3+) enables cell nucleus molecular imaging of prostate cancer cells: the last $600 \mathrm{~nm}$. Cancer Res, 62:7018-24.

Hegi ME, Diserens AC, Gorlia T, et al. 2005. MGMT gene silencing and benefit from temozolomide in glioblastoma. $N$ Engl $J$ Med, 352:997-1003.

Hirose Y, Berger MS, Pieper RO 2001. Abrogation of the Chk1-mediated $\mathrm{G}(2)$ checkpoint pathway potentiates temozolomide-induced toxicity in a p53-independent manner in human glioblastoma cells. Cancer Res, 61:5843-9.

Hirose Y, Katayama M, Stokoe D, et al. 2003. The p38 mitogen-activated protein kinase pathway links the DNA mismatch repair system to the G2 checkpoint and to resistance to chemotherapeutic DNA-methylating agents. Mol Cell Biol, 23:8306-15.

Huisgen R. 1984. In: 1,3-Dipolar Cycloaddition Chemistry. Padwa A (ed). New York: Wiley. pp. 1-176.

Kim EY, Gronewold C, Chatterjee A, et al. 2005. Oligosaccharide mimics containing galactose and fucose specifically label tumour cell surfaces and inhibit cell adhesion to fibronectin. Chembiochem, 6:422-31.

Kohn M, Breinbauer R. 2004. The Staudinger ligation-a gift to chemical biology. Angew Chem Int Ed Engl, 43:3106-16.

Kolb HC, Finn MG, Sharpless KB. 2001. Click chemistry: diverse chemical function from a few good reactions. Angew Chem Int Ed Engl, 40:2004-21.

Kolb HC, Sharpless KB. 2003. The growing impact of click chemistry on drug discovery. Drug Discov Today, 8:1128-37.

Mazmanian SK, Liu G, Ton-That H, et al. 1999. Staphylococcus aureus sortase, an enzyme that anchors surface proteins to the cell wall Science, 285:760-3.

Merdan T, Kopecek J, Kissel T. 2002. Prospects for cationic polymers in gene and oligonucleotide therapy against cancer. Adv Drug Deliv Rev, 54:715-58.

Merriefield RB. 1963. Solid phase peptide synthesis. I The synthesis of a tetrapeptide. J Am Chem Soc, 85:2149-54.

Newlands ES, Blackledge GR, Slack JA, et al. 1992. Phase I trial of temozolomide (CCRG 81045: M\&B 39831: NSC 362856). Br J Cancer, 65:287-91.

Newlands ES, Stevens MF, Wedge SR, et al. 1997. Temozolomide: a review of its discovery, chemical properties, pre-clinical development and clinical trials. Cancer Treat Rev, 23:35-61.

Nicoletti I, Migliorati G, Pagliacci MC, et al. 1991. A rapid and simple method for measuring thymocyte apoptosis by propidium iodide staining and flow cytometry. J Immunol Methods, 139:271-9.

Osoba D, Brada M, Yung WK, et al. 2000. Health-related quality of life in patients treated with temozolomide versus procarbazine for recurrent glioblastoma multiforme. J Clin Oncol, 18:1481-91.

Palmer DJ, Ng P. 2005. Helper-dependent adenoviral vectors for gene therapy. Hum Gene Ther, 16:1-16.
Park JA, Joe YA, Kim TG, et al. 2006. Potentiation of antiglioma effect with combined temozolomide and interferon-beta. Oncol Rep, 16:1253-60.

Parthasarathy R, Subramanian S, Boder ET 2007. Sortase A as a novel molecular "stapler" for sequence-specific protein conjugation. Bioconjug Chem, 18:469-76.

Rao PN. 1980. The molecular basis of drug-induced G2 arrest in mammalian cells. Mol Cell Biochem, 29:47-57.

Raymond E, Izbicka E, Soda H, et al. 1997. Activity of temozolomide against human tumor colony-forming units. Clin Cancer Res, 3:1769-74.

Riccardi A, Mazzarella G, Cefalo G, et al. 2003. Pharmacokinetics of temozolomide given three times a day in pediatric and adult patients. Cancer Chemother Pharmacol, 52:459-64.

Rostovtsev VV, Green LG, Fokin VV, et al. 2002. A stepwise huisgen cycloaddition process: copper(I)-catalyzed regioselective "ligation" of azides and terminal alkynes. Angew Chem Int Ed Engl, 41:2596-9.

Seymour LW. 1992. Passive tumor targeting of soluble macromolecules and drug conjugates. Crit Rev Ther Drug Carrier Syst, 9:135-87.

Singer S, Ehemann V, Brauckhoff A, et al. 2007. Protumorigenic overexpression of stathmin/Op18 by gain-of-function mutation in $\mathrm{p} 53$ in human hepatocarcinogenesis. Hepatology, 46:759-68.

Storm G, Crommelin DJA. 1997. Colloidal systems for tumor targeting. Hybridoma, 16:119-25.

Tabin CJ, Hoffmann JW, Goff SP, et al. 1982. Adaptation of a retrovirus as a eucaryotic vector transmitting the herpes simplex virus thymidine kinase gene. Mol Cell Biol, 2:426-36.

Thomas HC, Lame MW, Wilson DW, et al. 1996. Cell cycle alterations associated with covalent binding of monocrotaline pyrrole to pulmonary artery endothelial cell DNA. Toxicol Appl Pharmacol, 141:319-29.

Tsang LL, Farmer PB, Gescher A, et al. 1990. Characterisation of urinary metabolites of temozolomide in humans and mice and evaluation of their cytotoxicity. Cancer Chemother Pharmacol, 26:429-36.

Tschaharganeh D, Ehemann V, Nussbaum T, et al. 2007. Non-specific effects of siRNAs on tumor cells with implications on therapeutic applicability using RNA interference. Pathol Oncol Res, 13:84-90.

Vives E, Brodin P, Lebleu B. 1997. A truncated HIV-1 Tat protein basic domain rapidly translocates through the plasma membrane and accumulates in the cell nucleus. $J$ Biol Chem, 272:16010-17.

Walker MD, Alexander E Jr, Hunt WE, et al. 1978. Evaluation of BCNU and/or radiotherapy in the treatment of anaplastic gliomas. A cooperative clinical trial. J Neurosurg, 49:333-43.

Walton TJ, Li G, Seth R, et al. 2008. DNA demethylation and histone deacetylation inhibition co-operate to re-express estrogen receptor beta and induce apoptosis in prostate cancer cell-lines. Prostate, 68:210-22.

Yeo Y, Chen AU, Basaran OA, et al. 2004. Solvent exchange method: a novel microencapsulation technique using dual microdispensers. Pharm Res, 21:1419-27. 
